\title{
Получение пористого кремния путем спекания нанопорошка
}

\author{
(C) Е.В. Астрова, В.Б. Воронков, А.В. Нащекин, А.В. Парфреньева, \\ Д.А. Ложкина, М.В. Томкович, Ю.А. Кукушкина
}

Физико-технический институт им. А.Ф. Иофрфе Российской академии наук, 194021 Санкт-Петербург, Россия

E-mail: east@mail.ioffe.ru

(Поступила в Редакцию 12 ноября 2018 г.

В окончательной редакции 22 ноября 2018 г.

Принята к публикации 26 ноября 2018 г.)

Хорошо известный способ получения слоев макропористого кремния с помощью электрохимического и фотоэлектрохимического травления монокристаллических пластин является малопроизводительным и дорогим. В качестве альтернативного метода получения объемного макропористого кремния можно использовать высокотемпературное спекание порошка Si. B работе проведены исследования процесса спекания нанопорошка, предварительно прошедшего холодную компрессию всухую (без связующих добавок). Изучены свойства полученного материала (микроструктура, плотность и электропроводность) в зависимости от температуры и времени отжига. Обсуждаются способы изменения пористости спеченных образцов и методы определения площади внутренней поверхности.

DOI: 10.21883/FTP.2019.04.47455.9019

\section{1. Введение}

Наиболее известный и широко применяемый метод получения пористого кремния - это электрохимическое травление монокристаллических пластин в растворе плавиковой кислоты [1]. В зависимости от типа проводимости и удельного сопротивления пластин, состава электролита и режима анодирования, можно получить слои с разной пористостью (микро-, мезо- и макропористые) и соответственно с разным размером кристаллитов Si и пор (<2 нм, 2-50нм и > 50 нм). Эти материалы нашли широкое применение в самых разных отраслях техники, в связи с чем появилась потребность в более производительном и дешевом методе получения объемного пористого кремния. Для изготовления мезопористого кремния было предложено использовать магний-термическое восстановление пористого $\mathrm{SiO}_{2}$ [2] и различные варианты бестокового травления: каталитическое (metal-assisted etching) [3] и окрашивающее (stain etching) [4], а макропористый кремний формировать с помощью спекания механически измельченного поликристаллического или монокристаллического $\mathrm{Si}$ [5-7] или просто методом холодной компрессии [8]. Имеющиеся в литературе данные указывают на то, что скорость спекания сильно зависит от размера частиц $\mathrm{Si}$, состояния их поверхности, а также от условий компрессии и отжига. Нам известна лишь одна работа, посвященная спеканию ультрамелкого порошка $\mathrm{Si}$, полученного из моносилана [9]. Наиболее плотные и прочные образцы формируются в процессе одновременного воздействия высокого давления и температуры (hot pressed) [10-13]. Их пористость составляет единицы процентов, и используют их в основном в технологии солнечных элементов. Для ряда применений, например, для пролонгированной доставки лекарственных препаратов или формирования анодов литий-ионных аккумуляторов, требуется макропористый материал с более высокой пористостью. В этом случае больше подходит холодная компрессия и последующее спекание.

Настоящая работа ставит своей целью изучить процесс формирования объемного пористого кремния с помощью спекания нанопорошка, исследовать его свойства и методы последующей модификации.

\section{2. Методика эксперимента}

Исходным материалом служил коммерческий продукт китайской фирмы Hongwu Nanometer, полученный методом термического разложения силана с помощью лазера. Порошок состоял из сферических частиц размером 30-50нм с содержанием $\mathrm{Si} \geq 99 \%$, удельная площадь поверхности составляла 90-95 $\mathrm{m}^{2} / \Gamma$. Компрессия осуществлялась в пресс-форме, в которую засыпалось 15-20 мг порошка. Прессование проводилось всухую с помощью гидравлического пресса. Эксперименты проводились с образцами, спрессованными при давлении 140-210 МПа. Полученные таблетки имели диаметр $\sim 6$ мм и толщину 400-600 мкм.

Спекание проводилось при температурах $T=750-1250^{\circ} \mathrm{C}$ в муфельной печи с горизонтальной кварцевой трубой диаметром 46 мм, продуваемой аргоном высокой чистоты, 99.998\% (ТУ 6-21-12-94), расход газа составлял 100 л/ч. Содержание примесей в $\mathrm{Ar}:<2 \cdot 10^{-4 \%} \quad \mathrm{O}_{2},<3 \cdot 10^{-4 \%} \quad \mathrm{H}_{2} \mathrm{O}$. Плотность спрессованного и спеченного материалов определялась как $\rho=m / l S$, где $m$ и $l-$ масса и толщина таблетки, $S$ - ее площадь. Из плотности вычислялась величина 


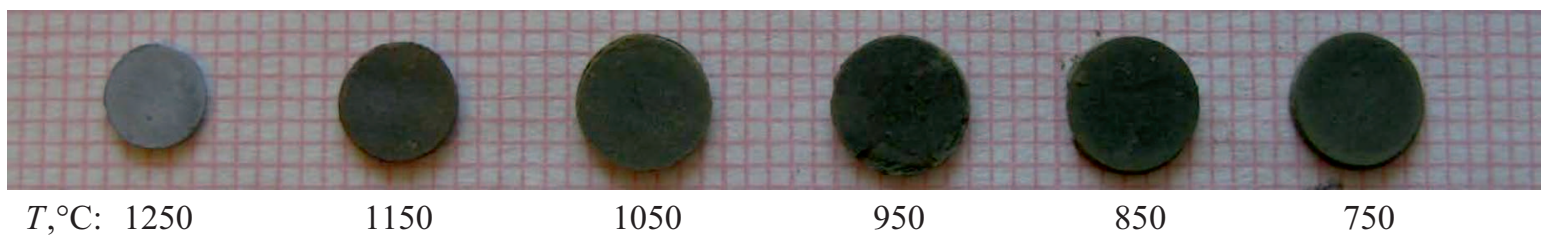

Рис. 1. Фотография образцов, подвергшихся отжигу при $T=750-1250^{\circ}$ С. Плотность компактов до отжига 0.92 г $/ \mathrm{cm}^{3}$.

пористости $p=\left(1-\rho / \rho_{m}\right) 100 \%$, где $\rho_{m}-$ плотность монолитного материала. В случае чистого кремния $\rho_{m}=\rho_{\mathrm{Si}}=2.33 \Gamma / \mathrm{cm}^{3}$.

Для нахождения истинной плотности исходного и спеченного материалов использовалась гелевая пикнометрия на пикнометре AccuРус1330 фирмы Micromeritics. Удельная поверхность спеченного пористого кремния определялась методом БЭТ (Браунера, Эммета и Теллера) по изотерме адсорбции азота при температуpe $77 \mathrm{~K}$ с помощью адсорбционно-структурного анализатора ASAP 2020 фирмы Micromeritics. Для определения удельного электрического сопротивления использовалась четырехзондовая установка с головкой фирмы Jandel (Великобритания). Электронно-микроскопические исследования (SEM) проводились с помощью растрового электронного микроскопа JSM 7001F (JEOL, Япония). Для изучения зависимости свойств материала от температуры спекания использовались изохронный и изотермический отжиги.

\section{3. Изохронный отжиг}

Для исследования зависимости свойств материала от температуры спекания использовался изохронный отжиг в течение 1 ч. Были изготовлены две серии образцов. Серия 1 после прессовки имела плотность $\rho_{c}=0.92$ г $/ \mathrm{cm}^{3}$ $(p=60.5 \%)$, серия $2-\rho_{c}=1.07 \Gamma / \mathrm{cm}^{3}(p=54.1 \%)$. При температуре отжига $T<1050^{\circ} \mathrm{C}$ плотность таблеток изменяется незначительно, а при более высоких температурах она резко возрастает, приближаясь к плотности монолитного кремния. После термообработки при высокой температуре происходит значительная усадка материала, которая выражается в уменьшении диаметра и толщины таблеток. На рис. 1 хорошо видно изменение диаметра и цвета спеченных образцов. Спекание при $1250^{\circ} \mathrm{C}$ приводит к тому, что образец приобретает серый цвет, как у монолитного кремния, а его пористость уменьшается до $11.6 \%$.

На рис. 2 показано, как изменяется плотность спеченных образцов в зависимости от температуры отжига. Видно, что исходная плотность после прессования $\rho_{c}$ оказывает влияние на плотность образцов после спекания, а именно более компактное прессование снижает температуру спекания.

Электронно-микроскопические исследования структуры проводились на сколе образца и на его поверхности. При спекании наночастицы соединяются между

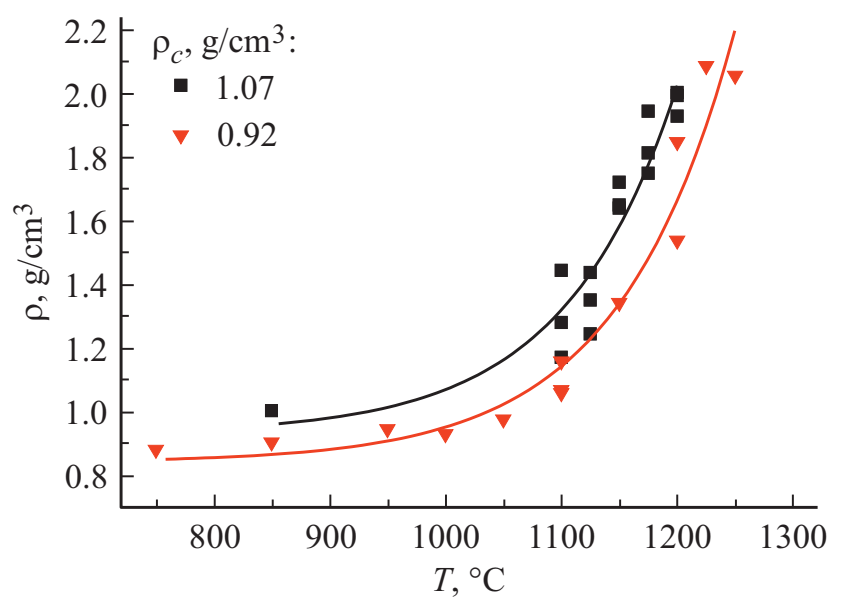

Рис. 2. Зависимости плотности спеченного материала от температуры отжига для образцов двух серий с разной исходной плотностью компрессии $\rho_{c}=0.92$ и $1.07 \Gamma / \mathrm{cm}^{3}$.

собой с помощью перемычек и образуют более крупные зерна. Увеличение размера зерен и снижение пористости становятся заметными начиная с $T=1125^{\circ} \mathrm{C}$. На рис. 3 показано поперечное сечение образцов обеих серий. Хорошо видно, что при одинаковой температуре отжига из менее плотных исходных компактов формируется структура с меньшим размером зерен и большей пористостью, чем из более плотных компактов. Размер зерен $\mathrm{Si}$ и пор лежит в диапазоне от нескольких десятков до сотен нанометров, т.е. материал является макропористым. Следует отметить, что, в отличие от результатов работы [9], для большинства образцов отсутствовал градиент пористости по глубине, и микроструктура оставалась неизменной как в средней части образца, так и вблизи поверхности. Изменение пористости вблизи поверхности и образование корки наблюдалось только при высоких температурах отжига, $>1200^{\circ} \mathrm{C}$. На рис. 4 приводится изображение поверхности таблеток, где можно видеть, что крупнозернистая корка образуется в процессе отжига при $T>1225^{\circ} \mathrm{C}$. На поверхности этой корки появляется тонкая структура в виде ступенек роста.

\section{4. Изотермический отжиг}

Зависимость плотности таблеток от времени спекания $t$ для образцов серии 2 исследовалась при 

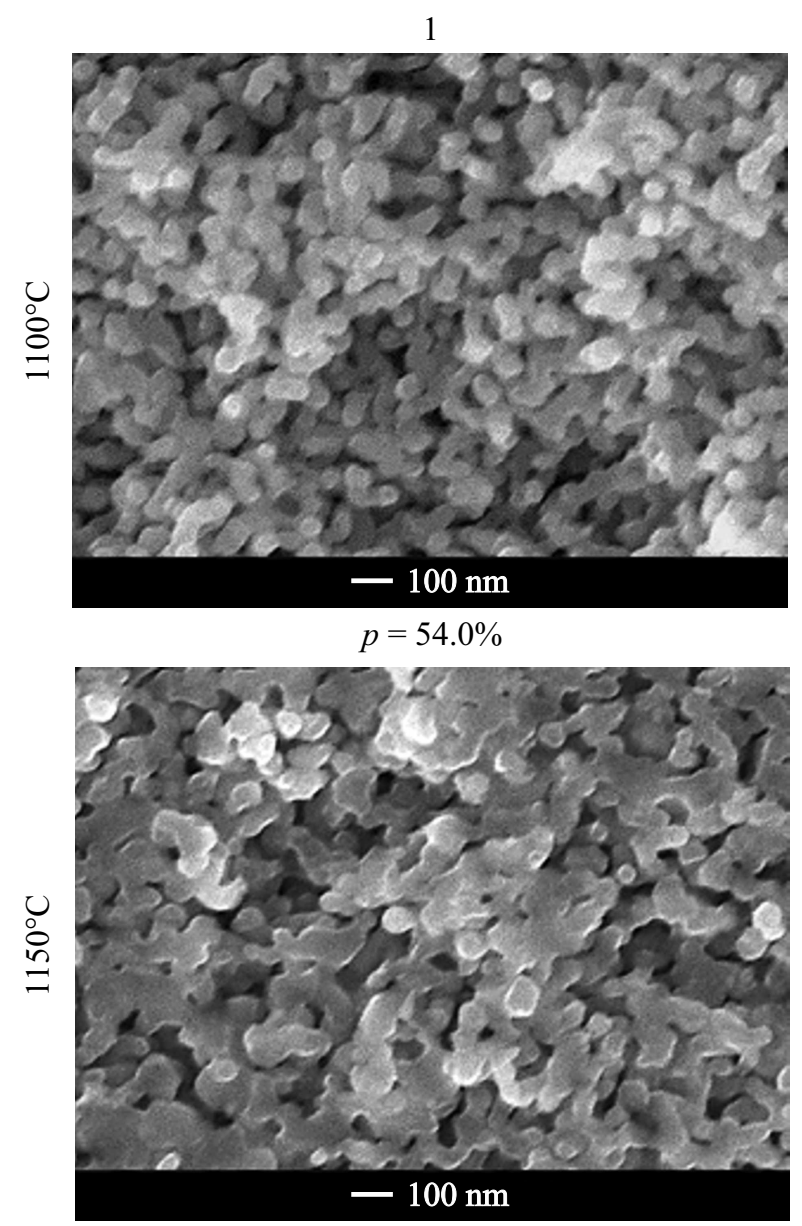

$p=42.0 \%$

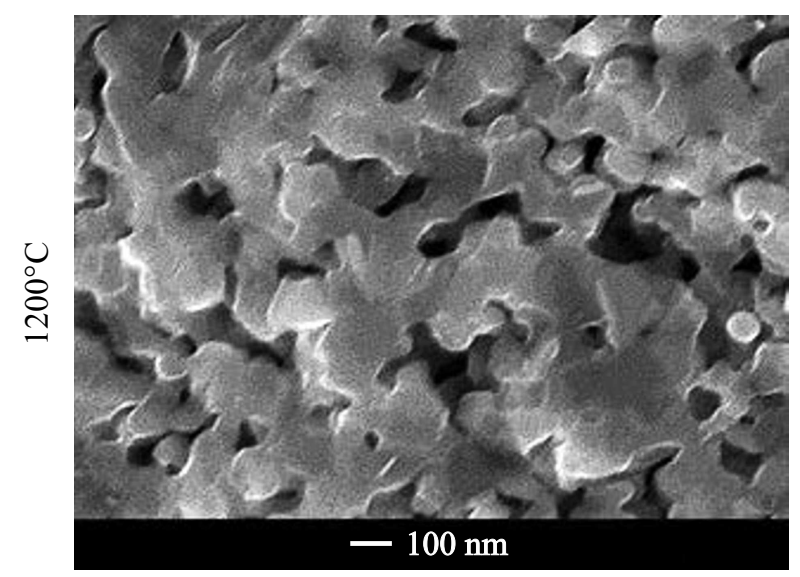

$p=34.0 \%$
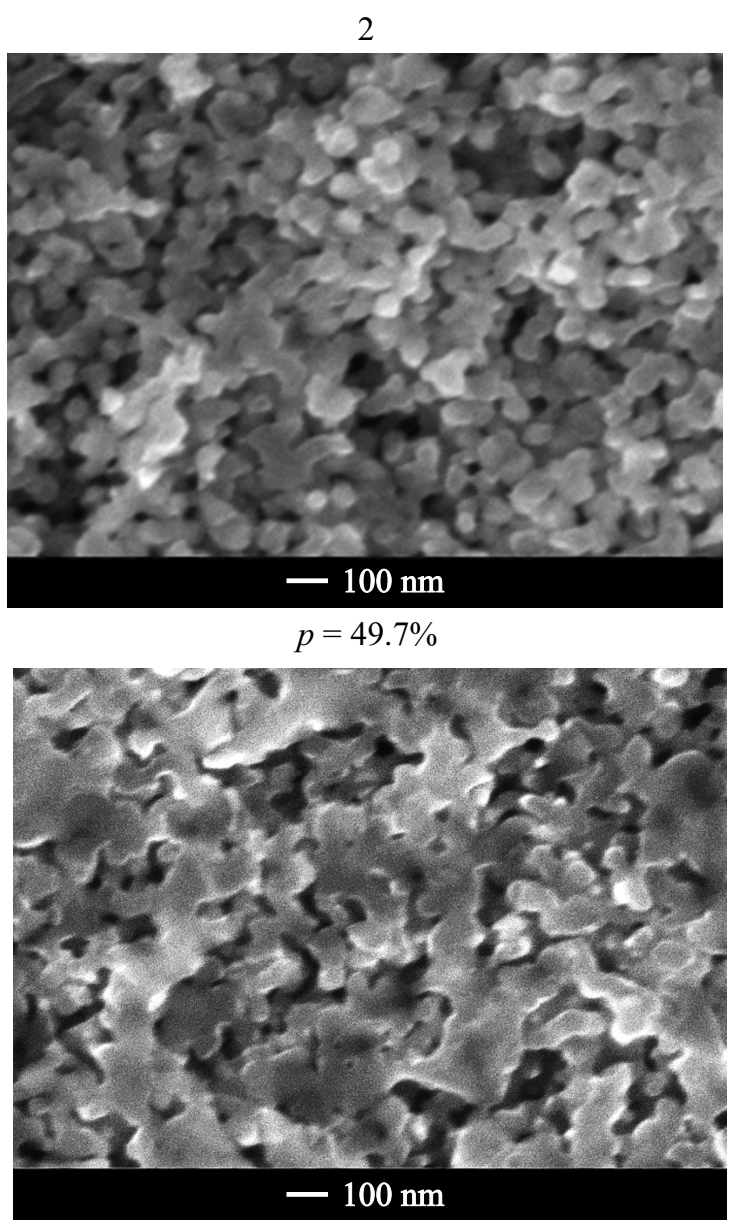

$p=32.0 \%$

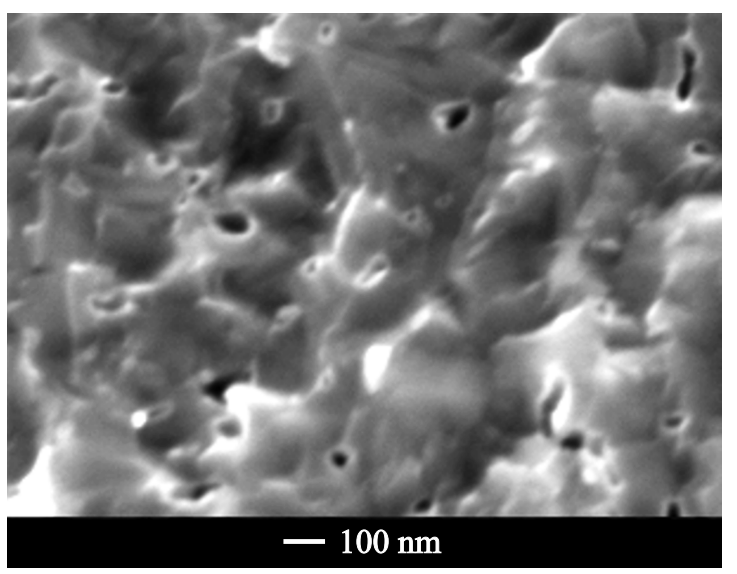

$p=13.9 \%$

Рис. 3. SЕМ-изображение поперечного сечения таблеток, спеченных при разных температурах: образцы серии $1\left(\rho_{c}=0.92\right.$ г $/ \mathrm{cm}^{3}$, слева) и серии 2 ( $\rho_{c}=1.07$ г $\mathrm{cm}^{3}$, справа). Отжиг 1 ч в $\mathrm{Ar}$.

$T=1125^{\circ}$ C. На рис. 5 показана зависимость, которая аппроксимируется экспоненциальной функцией

$$
\rho=A \exp \left(-\frac{t}{t_{0}}\right)+C
$$

где постоянная времени составляет $t_{0}=3.42$ ч.
Из рис. 6 видно, что со временем происходит увеличение размера зерен, а число пор снижается, подобно тому, как это происходит по мере увеличения температуры при изохронном отжиге. Структура и плотность образцов, отжигавшихся в течение 10 ч при $T=1125^{\circ} \mathrm{C}$, примерно такая же, как и образцов, отжигавшихся в течение 1 ч, но при $T=1150^{\circ} \mathrm{C}$. 


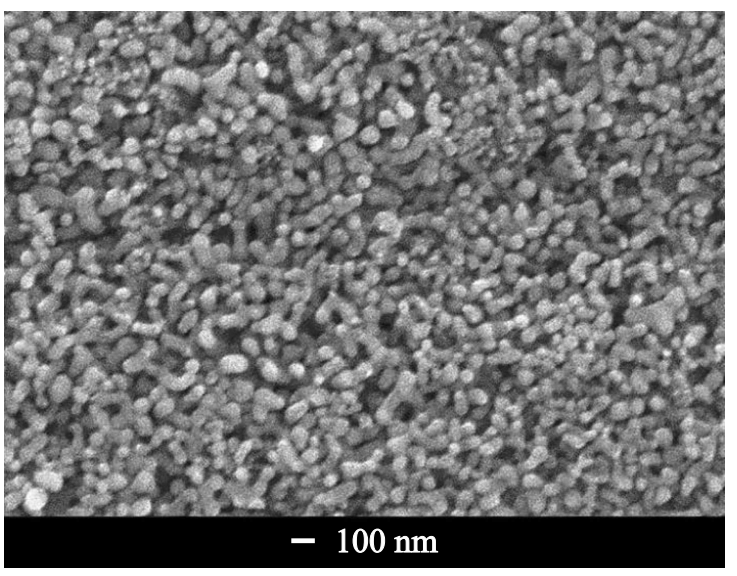

compacted

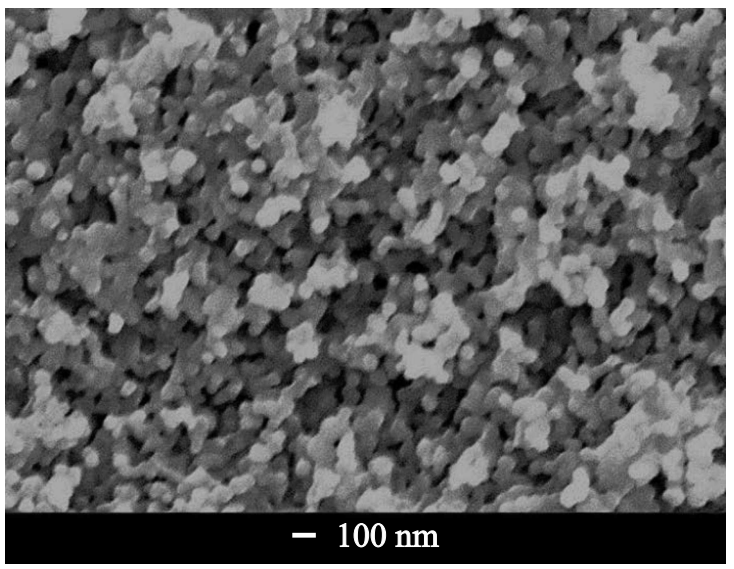

$1150^{\circ} \mathrm{C}$

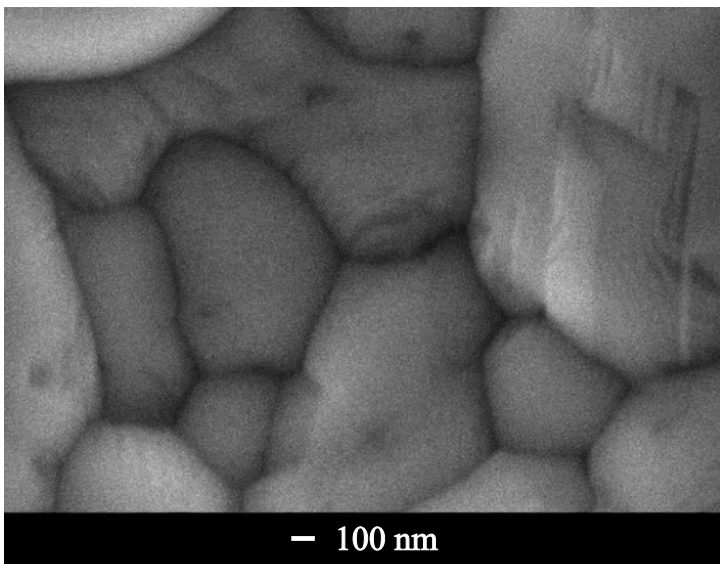

$1225^{\circ} \mathrm{C}$

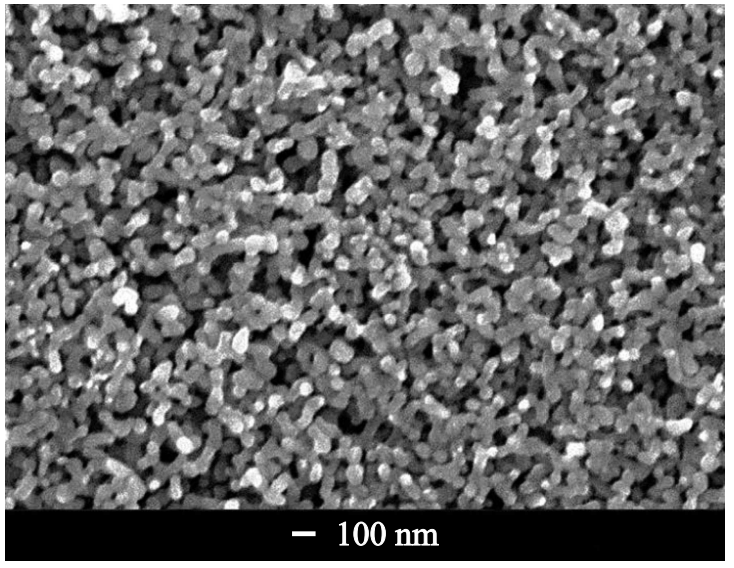

$1100^{\circ} \mathrm{C}$

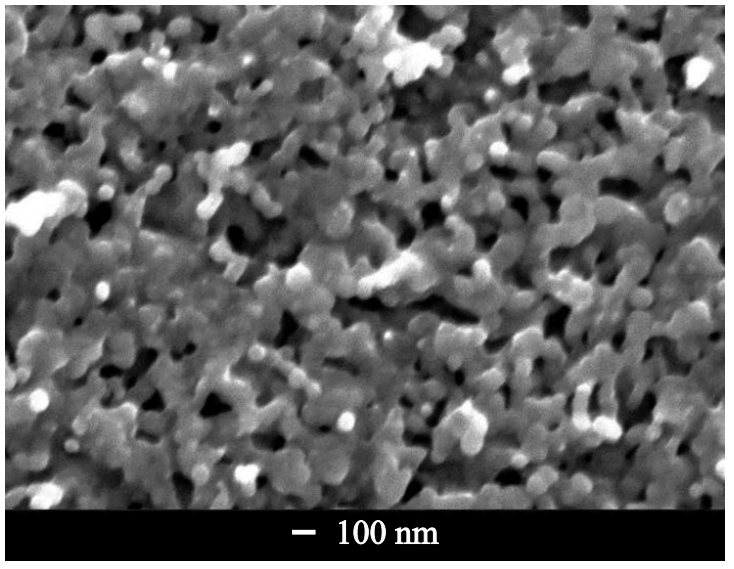

$1200^{\circ} \mathrm{C}$

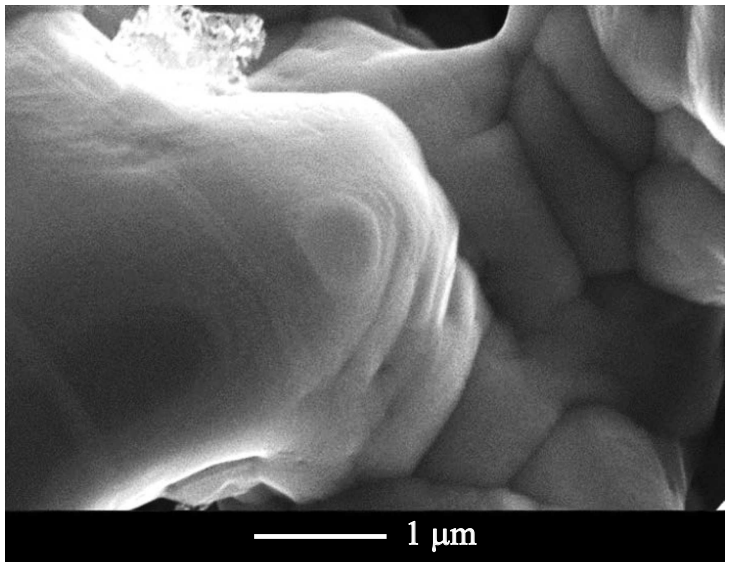

$1250^{\circ} \mathrm{C}$

Рис. 4. SEM-изображение поверхности образцов серии 1 , отожженных при разных температурах в течение 1 ч.

Управлять пористостью спеченных таблеток можно путем изменения плотности компакта. Однако здесь возможности по снижению плотности ограничиваются уменьшающейся механической прочностью таблеток. В наших экспериментах таблетки, имеющие после компрессии пористость $\sim 50 \%$, позволяли проводить над ними различные манипуляции, связанные с измерениями и отжигом. Рассмотрим возможности различных методов модификации свойств образцов после спекания.

\section{5. Окисление с последующим растворением окисла}

Формирование тонкого слоя окисла на поверхности открытых пор спеченных таблеток проводилось путем термического окисления на воздухе при $T=900^{\circ} \mathrm{C}$. Контроль толщины образовавшегося $\mathrm{SiO}_{2}$ осуществлялся с помощью эллипсометра на образце-свидетеле в виде полированной пластины монокристаллического 


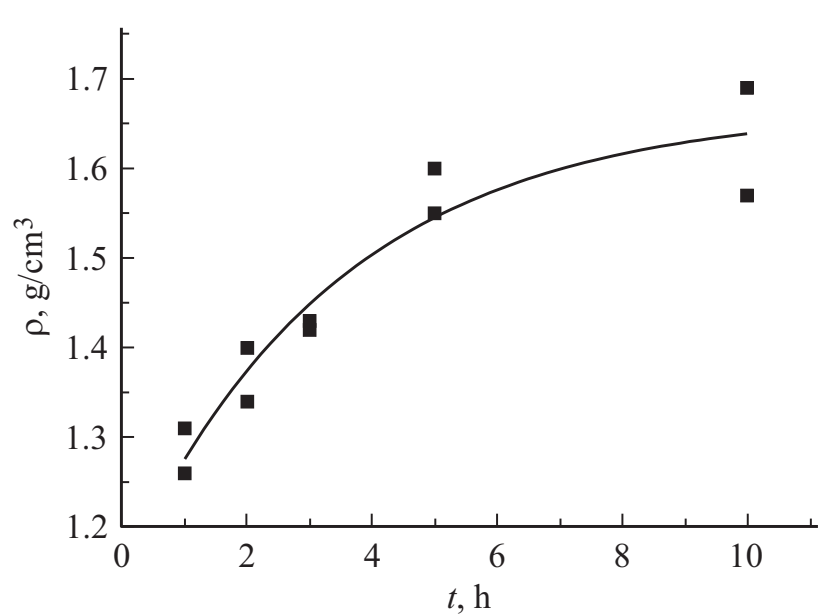

Рис. 5. Зависимость плотности спеченных таблеток от времени отжига $t$ при $T=1125^{\circ} \mathrm{C}$.

кремния. После проведения измерений массы, площади и толщины окисленной таблетки $\mathrm{SiO}_{2}$ растворялся. Для этого образцы погружались в раствор НF состава $\mathrm{HF}: \mathrm{EtOH}: \mathrm{H}_{2} \mathrm{O}$ в объемных долях $(5: 3: 50)$. Этиловый спирт добавляется для повышения смачиваемости поверхности. После промывки и сушки таблетки вновь взвешивались и измерялись их геометрические параметры. Типичная зависимость плотности спеченной таблетки от времени травления в растворе НF приведена на рис. 7. Быстрый начальный участок соответствует растворению основной части окисла, а следующий за ним более пологий - растворению окисла в глубинных слоях образца и растворению самого кремния.

В табл. 1 и 2 отражены результаты, полученные для двух образцов, \#22 и \#77, спекавшихся при разных температурах. Исходная пористость образца \#22 $p=50.2 \%$ (размер зерен Si 60-100нм), образца \#77 $p=45.5 \%$ (размер зерен Si 100-300 нм). Спекание проводилось при $T=1100$ и $1150^{\circ} \mathrm{C}$ соответственно.

Из табл. 1 видно, что окисление приводит к увеличению массы и плотности таблеток. При этом таблетка „распухает“, т.е. увеличиваются ее толщина $l$ и площадь $S$. Последнее неудивительно, так как объем грамм-молекулы диоксида кремния превышает объем кремния, из которого он образовался, в 2.27 раза. Прирост массы обусловлен присоединением кислорода. При образовании каждой молекулы $\mathrm{SiO}_{2}$ расходуется 1 атом кремния из подложки и 2 атома кислорода из воздуха. Поэтому для определения массы образовавшегося окисла следует $\Delta m^{\prime}$ умножить на отношение молекулярной массы $\mathrm{SiO}_{2}$ к грамм-атомному весу 2 атомов кислорода $60 / 32=1.875$. Полученная масса окисла равна $m\left(\mathrm{SiO}_{2}\right)=32.4$ мг, что составляет $92.6 \%$ всей массы окисленного образца. Плотность компактного материала такого состава $\rho_{m}=2.21 \Gamma / \mathrm{cm}^{3}$, с учетом которой рассчитана пористость окисленной таблетки.

Из массы образовавшегося $\mathrm{SiO}_{2}$, так же, как это делалось с помощью окислительно-гравиметрического метода для традиционного макропористого кремния [14], можно оценить площадь внутренней поверхности пор. Площадь поверхности пор в таблетке $A=m\left(\mathrm{SiO}_{2}\right) /\left[\rho\left(\mathrm{SiO}_{2}\right) \cdot d\left(\mathrm{SiO}_{2}\right)\right]$, где плотность окисла $\rho\left(\mathrm{SiO}_{2}\right)=2.2 \Gamma / \mathrm{cm}^{3}[15]$. Поделив $A$ на массу спеченного образца, получаем удельную площадь поверхности $A^{\prime}$. Аналогично из изменения массы после обработки в

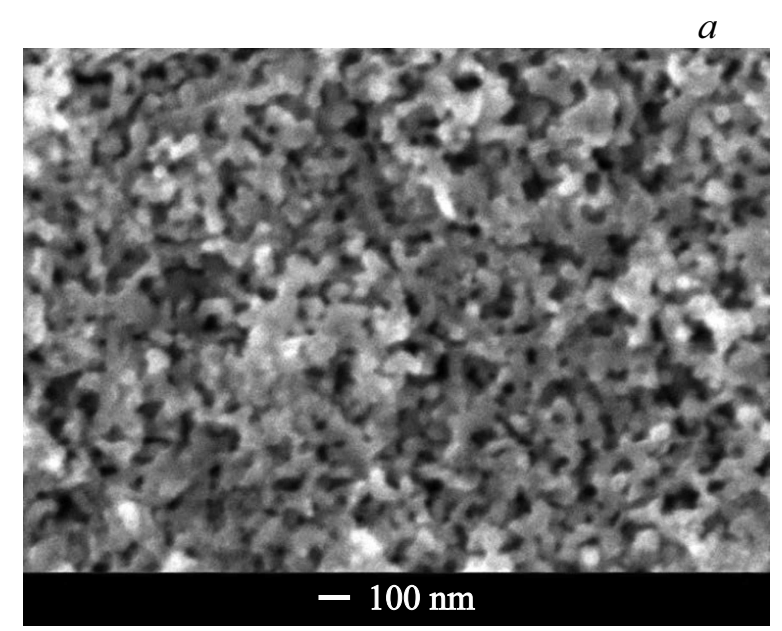

$b$

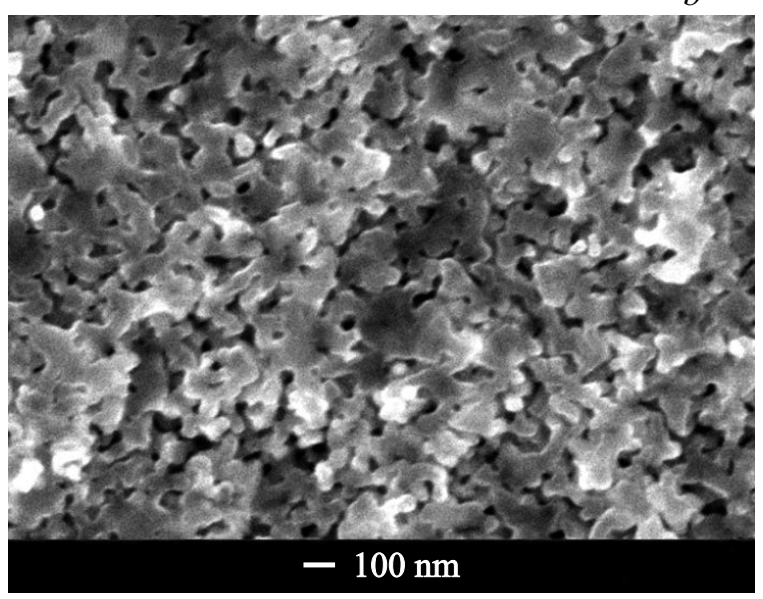

$c$

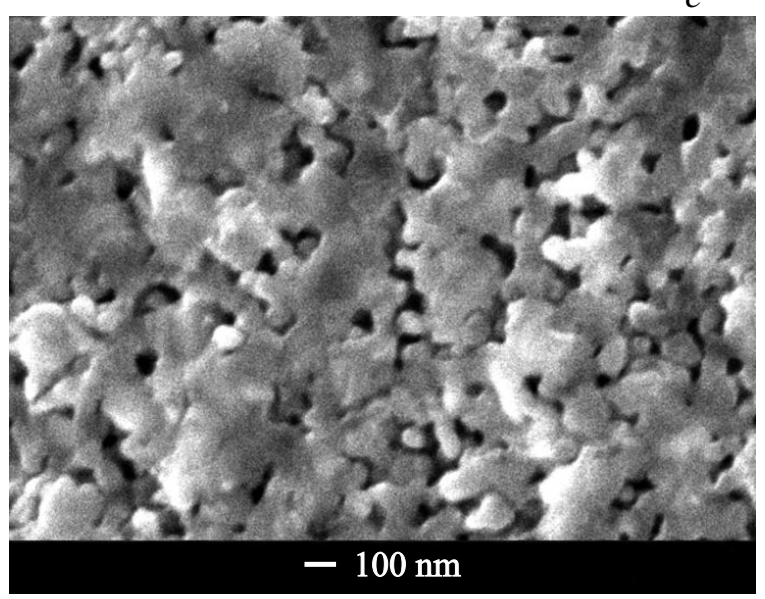

Рис. 6. Поперечное сечение образцов, отжигавшихся при $T=1125^{\circ} \mathrm{C}$ в течение: $1(a), 2(b), 10$ ч $(c)$. 
Таблица 1. Параметры образца \#22 после спекания, термического окисления и растворения окисла

\begin{tabular}{|c|c|c|c|}
\hline Параметры & $\begin{array}{c}\text { После спекания при } 1100^{\circ} \mathrm{C} \\
\qquad(1 \text { ч) }\end{array}$ & $\begin{array}{c}\text { После окисления } \\
(1 \text { ч) }\end{array}$ & $\begin{array}{c}\text { После обработки в НF } \\
\text { (1 ч) }\end{array}$ \\
\hline $\begin{array}{l}\text { Масса таблетки } m, \mathrm{м} \\
\text { Плотность } \rho, \Gamma / \mathrm{cm}^{3} \\
\text { Пористость } p, \% \\
\text { Толщина таблетки } l, \text { мкм } \\
\text { Площадь таблетки } S, \mathrm{Mм}^{2} \\
\text { Диаметр таблетки } D, \mathrm{Mм} \\
\text { Толщина окисла } d\left(\mathrm{SiO}_{2}\right), \mathrm{Hм} \\
\quad \Delta m^{\prime}, \mathrm{M \Gamma} \\
\quad \Delta m^{\prime \prime}, \mathrm{M \Gamma} \\
\quad m\left(\mathrm{SiO}_{2}\right), \text { мг } \\
\quad A, \mathrm{~cm}^{2} \\
A^{\prime}, \mathrm{M}^{2} / \Gamma \\
A^{\prime \prime}, \mathrm{m}^{2} / \Gamma\end{array}$ & $\begin{array}{c}17.7 \\
1.16 \\
50.2 \\
590 \\
25.97 \\
5.75 \\
\\
\\
\\
2888 \\
16.31\end{array}$ & $\begin{array}{c}35 \\
1.25 \\
43.4 \\
720 \\
38.83 \\
7.05 \\
51 \\
+17.3 \\
\\
32.4\end{array}$ & $\begin{array}{c}11.9 \\
0.94 \\
59.6 \\
453 \\
27.79 \\
5.95 \\
\\
-23.1 \\
2059 \\
17.3\end{array}$ \\
\hline
\end{tabular}

Примечание. $\Delta m^{\prime}$ - изменение массы относительно спеченного образца, $\Delta m^{\prime \prime}$ - изменение массы относительно окисленного образца, $m\left(\mathrm{SiO}_{2}\right)$ масса образовавшегося $\mathrm{SiO}_{2}, A-$ площадь внутренней поверхности образца, $A^{\prime}$ - площадь поверхности на 1 г спеченного образца, $A^{\prime \prime}-$ площадь поверхности на 1 г образца после обработки в HF.

Таблица 2. Параметры образца \#77 после спекания, термического окисления и растворения окисла

\begin{tabular}{|c|c|c|c|}
\hline Параметры & $\begin{array}{c}\text { После спекания при } 1150^{\circ} \mathrm{C} \\
(1 \text { ч) }\end{array}$ & $\begin{array}{c}\text { После окисления } \\
(1 \text { ч) }\end{array}$ & $\begin{array}{c}\text { После обработки в НF } \\
(100 \text { мин })\end{array}$ \\
\hline $\begin{array}{l}\text { Масса таблетки } m, \text { мг } \\
\text { Плотность } \rho, \Gamma / \mathrm{cm}^{3} \\
\text { Пористость } p, \% \\
\text { Толщина таблетки } l, \text { мкм } \\
\text { Площадь таблетки } S, \mathrm{Mм}^{2} \\
\text { Диаметр таблетки } D, \mathrm{Mм} \\
\text { Толщина окисла } d\left(\mathrm{SiO}_{2}\right), \mathrm{Hм} \\
\quad \Delta m^{\prime}, \mathrm{M \Gamma} \\
\Delta m^{\prime \prime}, \mathrm{M \Gamma} \\
m\left(\mathrm{SiO}_{2}\right), \mathrm{мг} \\
A, \mathrm{~cm}^{2} \\
A^{\prime}, \mathrm{M}^{2} / \Gamma \\
A^{\prime \prime}, \mathrm{M}^{2} / \Gamma\end{array}$ & $\begin{array}{c}14.2 \\
1.27 \\
45.5 \\
491 \\
22.80 \\
5.64 \\
\\
\\
\\
1655 \\
11.65\end{array}$ & $\begin{array}{c}20.8 \\
1.36 \\
39.6 \\
567 \\
27.07 \\
6.14 \\
34 \\
+6.6 \\
\\
12.38\end{array}$ & $\begin{array}{c}10.6 \\
0.77 \\
66.9 \\
525 \\
26.27 \\
5.78 \\
\\
-10.2 \\
1364 \\
12.86\end{array}$ \\
\hline
\end{tabular}

HF $\Delta m^{\prime \prime}$ находим $A=\Delta m^{\prime \prime} /\left[\rho\left(\mathrm{SiO}_{2}\right) \cdot d\left(\mathrm{SiO}_{2}\right)\right]$, что при делении на массу травленого образца дает $A^{\prime \prime}$. В силу того, что скорость растворения $\mathrm{SiO}_{2}$ в $\mathrm{HF}$ на несколько порядков превышает скорость растворения кремния, следовало ожидать, что проведенная обработка окисленного образца в HF растворит весь окисел. Однако мы видим, что $\Delta m^{\prime \prime}<m\left(\mathrm{SiO}_{2}\right)$. Следует обратить внимание на то, что после обработки в НF толщина таблетки стала меньше, чем исходная (после спекания), т.е. полностью растворились наружные слои таблетки. Это свидетельствует о том, что удаление окисла происходит неравномерно по глубине образца.

Аналогичный эксперимент был проведен с образцом \#77. Полученные результаты приведены в табл. 2.

Для образца \#77 наблюдаются такие же закономерности, как для \#22, с той лишь разницей, что после окисления массовая доля $\mathrm{SiO}_{2}$ в нем значительно меньше, чем в образце \#22, и составляет $59.5 \%$ от общей массы.
Последнее обусловлено большим размером зерен и соответственно меньшей площадью окисляемой поверхности кремния. Плотность такого компактного материала $\rho_{m}=2.25 \Gamma / \mathrm{cm}^{3}$. Снижение доли окисла в образце \#77 закономерно отразилось и на полученных результатах: в меньшем увеличении объема после окисления и меньшей удельной площади поверхности $A^{\prime}$ и $A^{\prime \prime}$. Обработка в HF привела к уменьшению толщины, но она осталась больше, чем толщина исходного образца \#77. Прочность таблетки после проведенных обработок сильно уменьшилась, что привело к ее растрескиванию. Последнее, по всей видимости, связано с увеличением пористости и появлением в окисленном образце механических напряжений в силу значительного увеличения объема окисной пленки по сравнению с объемом кремния, из которого она образовалась. Из проведенных экспериментов видно, что модификация спеченного макропористого кремния с помощью окисления и последующего растворения 


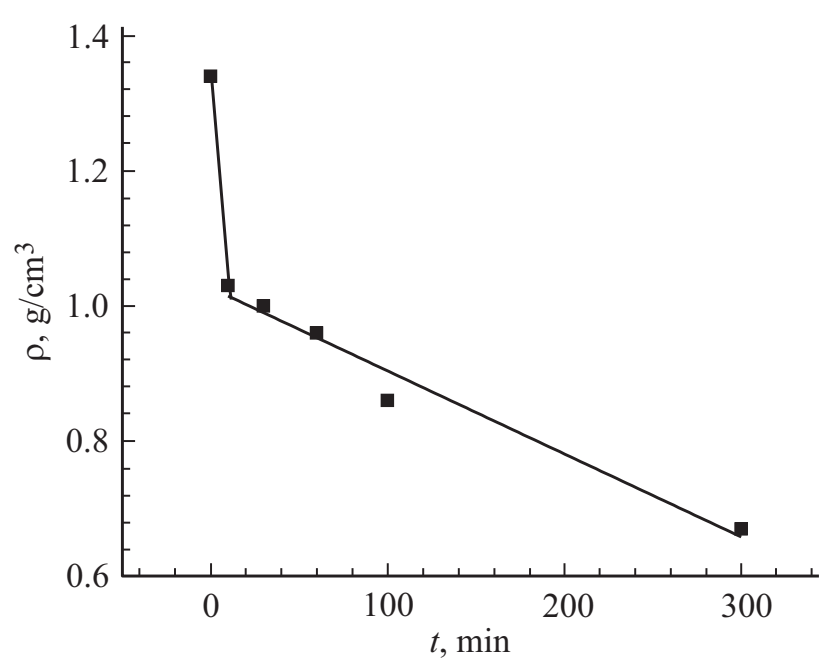

Рис. 7. Изменение плотности окисленного спеченного образца в зависимости от времени травления $t$ в растворе HF.

окисла позволяет увеличить пористость и площадь внутренней поверхности.

\section{6. Кинетика растворения в HF}

Таблетки после компрессии, помещенные в воду или этиловый спирт, сохраняли свою целостность, а при опускании в раствор плавиковой кислоты тут же рассыпались на мелкие части. Последнее обстоятельство, по-видимому, связано с наличием на поверхности кремниевых наночастиц тонкого слоя естественного окисла, толщиной $\sim 2$ нм, который растворяется в НF. Спеченные же образцы сохраняли целостность в плавиковой кислоте, но со временем изменяли свою массу и толщину. На рис. 8 представлено изменение плотности образца \#79 в зависимости от времени травления, а в табл. 3 приведены результаты эксперимента, проведенного на

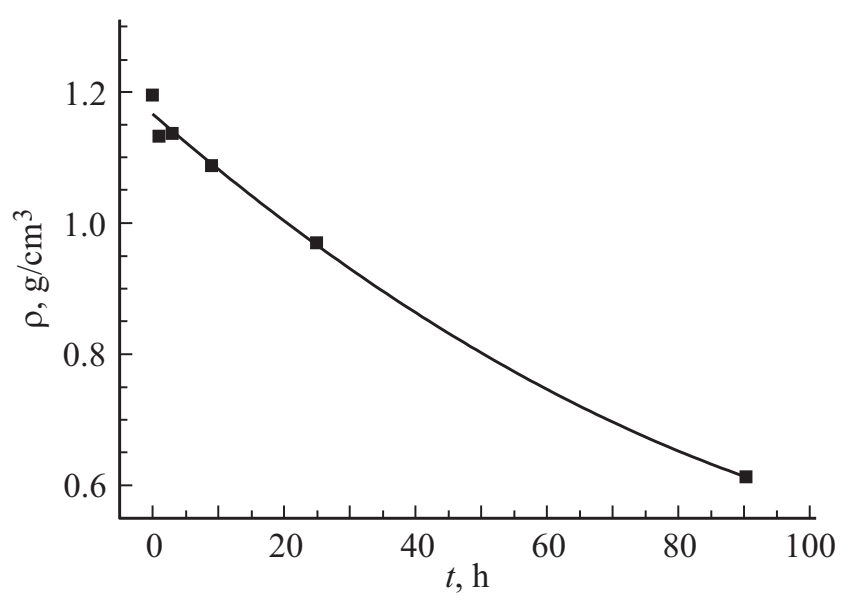

Рис. 8. Зависимость плотности образца от времени травления $t$ в растворе НF.
Таблица 3. Параметры образцов \#79 и \#80 до и после травления в растворе $\mathrm{HF}$

\begin{tabular}{l|c|c}
\hline \multicolumn{1}{c|}{ Параметр } & $\# 79$ & $\# 80$ \\
\hline Время травления $t$, ч & 90.4 & 15.5 \\
Масса таблетки до травления $m_{0}$, мг & 16.2 & 15.0 \\
Исходная плотность $\rho$, г $/ \mathrm{cm}^{3}$ & 1.19 & 1.26 \\
Исходная пористость $p, \%$ & 48.7 & 45.9 \\
Исходная толщина таблетки $l$, мкм & 546 & 482 \\
Масса таблетки после травления $m_{f}$, мг & 5.4 & 11.4 \\
Плотность после травления $\rho, \Gamma / \mathrm{cm}^{3}$ & 0.61 & 0.98 \\
Пористость после травления $p, \%$ & 73.7 & 57.9 \\
Толщина таблетки после травления $l$, мкм & 355 & 469 \\
Площадь таблетки $S$, мм ${ }^{2}$ & 24.82 & 24.74 \\
Изменение массы $\Delta m=m_{0}-m_{f}, \mathrm{M \Gamma}$ & -10.8 & -3.6 \\
Толщина растворенного слоя $d_{\mathrm{Si}}, \mathrm{HM}$ & 45.2 & 7.75 \\
$A, \mathrm{~cm}^{2}$ & 1025 & 1994 \\
$A^{\prime}, \mathrm{m}^{2} / \Gamma$ & 6.3 & 13.29 \\
$A^{\prime \prime}, \mathrm{m}^{2} / \Gamma$ & 18.98 & 17.49
\end{tabular}

образцах \#79 и \#80, которые подверглись травлению в том же растворе $\mathrm{HF}: \mathrm{EtOH}: \mathrm{H}_{2} \mathrm{O}=5: 3: 50$.

Видно, что, несмотря на очень малую скорость растворения кремния в плавиковой кислоте, обработка спеченного макропористого кремния в растворе НF приводит к уменьшению массы и увеличению пористости. Это происходит благодаря высокой площади поверхности. Использовать массу растворенного в НF кремния для определения площади поверхности пористого кремния $\mathrm{Si}$ впервые было предложено в [16]. В соответствии с литературными данными, скорость травления $\mathrm{Si}$ при комнатной температуре в 5\%-м растворе HF составляет $0.5 \mathrm{Hм} /$ [ [17]. Отсюда можно оценить толщину кремния $d_{\mathrm{Si}}$, растворенного за время обработки в $\mathrm{HF}$, и площадь внутренней поверхности таблетки $A=\Delta m / \rho_{\mathrm{Si}} d_{\mathrm{Si}}$, а затем и удельную площадь поверхности исследованных образцов $A^{\prime}=A / m_{0}$ и $A^{\prime \prime}=A / m_{f}$. Из табл. 3 можно видеть, что длительное травление образцов позволяет значительно повысить их пористость и удельную площадь поверхности. Если сравнивать между собой образцы \#77 и \#80, имеющие близкую исходную плотность, можно видеть, что их площади поверхности, найденные из изменения массы при окислении и из изменения массы при растворении кремния в $\mathrm{HF}$, дают близкие значения: $A^{\prime}=11.65$ и $13.29 \mathrm{M}^{2} /$ г соответственно.

\section{7. Адсорбция азота и пикнометрия}

Для определения удельной поверхности методом БЭТ понадобилось значительное количество материала. Было изготовлено 30 таблеток с исходной плотностью компрессии $\rho_{c}=1.07 \Gamma / \mathrm{cm}^{3}$ и проведено их спекание при $1150^{\circ} \mathrm{C}$. Среднее значение плотности полученных таблеток составило $\rho=1.60$ г/ $\mathrm{cm}^{3}$, пористость $32 \%$, а суммарная масса 0.5757 г. На рис. 9 приведена изотерма адсорбции азота, которую можно отнести к типу II, ха- 


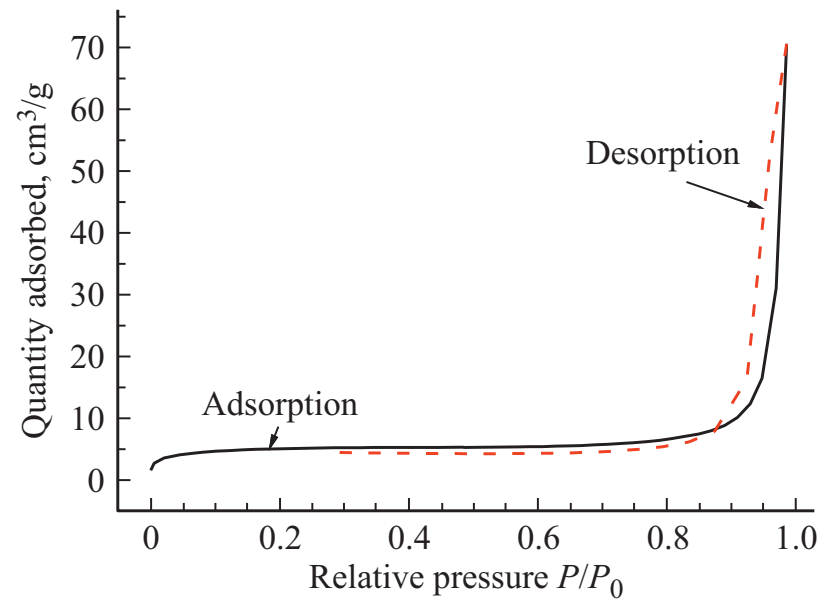

Рис. 9. Изотерма адсорбции азота для кремниевых таблеток, спеченных при $T=1150^{\circ} \mathrm{C}$.

рактерному для непористых материалов. По результатам анализа этой изотермы, полученной при температуре $77 \mathrm{~K}$, проведено определение удельной поверхности в области относительных давлений $P / P_{0}=0.001-0.16$ и суммарного объема пор в точке $P / P_{0}=0.99$. Полученное значение удельной поверхности составило $A^{\prime}=18.58 \mathrm{M}^{2} / \Gamma$, т. е. уменьшилось по сравнению с определенным для исходного порошка в $\sim 5$ раз. Наличие незначительной петли гистерезиса в области высоких давлений, $P / P_{0}>0.90$, обусловлено явлением капиллярной конденсации адсорбтива в промежутках между частицами. Суммарный объем пор $0.10 \mathrm{~cm}^{3} / \Gamma$ в точке $P / P_{0}=0.99$, по всей вероятности, соответствует сконденсированному азоту в промежутках между частицами.

Пикнометрия нанопорошка $\mathrm{Si}$ показала, что исходные наночастицы кремния имеют плотность 2.34 г/ $\mathrm{cm}^{3}$, практически равную плотности монокристаллического кремния, что говорит об отсутствии в них пор. Для спеченных при $1150^{\circ} \mathrm{C}$ таблеток истинная пикномет-

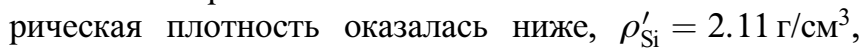
что соответствует пористости $9.44 \%$, обусловленной закрытыми порами. Таким образом, доля закрытых пор в общем объеме пор для образцов, спекавшихся при $T=1150^{\circ} \mathrm{C}$, составляет примерно одну треть.

\section{8. Обсуждение результатов}

Данные комбинационного рассеяния света свидетельствуют о том, что как исходный нанопорошок, так и спеченные образцы имеют кристаллическую структуру. Оценим размер зерен спеченного макропористого кремния исходя из экспериментально найденной удельной площади поверхности $A^{\prime}$. Для этого удобно использовать приближение, согласно которому структура материала представляется в виде плотноупакованных шаров диаметром $d$. Из соотношения $A^{\prime}=6 / \rho_{\mathrm{Si}}^{\prime} d$ для $A^{\prime}=18.58 \mathrm{M}^{2} / \Gamma$ и $\rho_{\mathrm{Si}}^{\prime}=2.11 \Gamma / \mathrm{cm}^{3}$ следует $d=153 \mathrm{Hм}$. Этот размер неплохо согласуется с данными SEM для образца \#44, подвергшегося спеканию при той же температуре $1150^{\circ} \mathrm{C}$ (рис. 3).

Следует отметить, что использование термического окисления или растворения кремния в НF для определения площади поверхности пор более удобно, чем измерения методом БЭТ, так как не требует большого количества материала и может быть проведено на одной таблетке. Однако имеется значительная неопределенность как в скорости окисления, так и в скорости растворения $\mathrm{Si}$, поскольку для корректных измерений требуется использовать образцы-свидетели, свойства которых (уровень легирования, кристаллографическая ориентация и состояние поверхности) могут отличаться от свойств исследуемого пористого образца. Помимо этого для определения площади поверхности следует наращивать очень тонкий слой окисла (или растворять тонкий слой кремния), толщина которого много меньше размера зерен, с тем чтобы площадь внутренней поверхности в результате обработки не сильно изменялась. В нашем случае небольших образцов выполнение этого требования привело бы к слишком малому изменению массы $\Delta m^{\prime}$ или $\Delta m$ и не позволило бы ее надежно измерить. Таким образом, опробованные в работе методы могут быть использованы лишь для ориентировочной оценки площади поверхности и ее изменений. Как видно, оба предлагаемые метода дали заниженные по сравнению с методом БЭТ значения.

Измерения удельного сопротивления спеченных образцов показали, что электропроводность возрастает с температурой отжига; это свидетельствует о появлении связной структуры. На рис. 10 зависимость удельного электрического сопротивления $\rho_{\mathrm{el}}$ от температуры отжига представлена в полулогарифмическом масштабе. Высокой температуре отжига $1250^{\circ} \mathrm{C}$ соответствует низкое удельное сопротивление $1.4 \mathrm{OM} \cdot \mathrm{cm}$. С помощью термозонда было определено, что этот низкоомный образец обладает проводимостью $p$-типа, т. е. присутствует акцепторная примесь, по-видимому, алюминий.

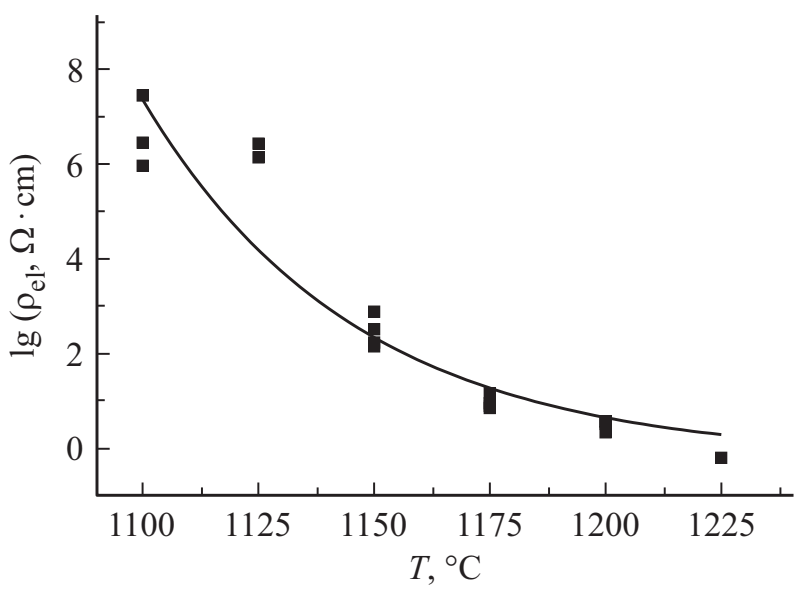

Рис. 10. Зависимость удельного электрического сопротивления спеченного кремния от температуры отжига. Время отжига 1 ч. 


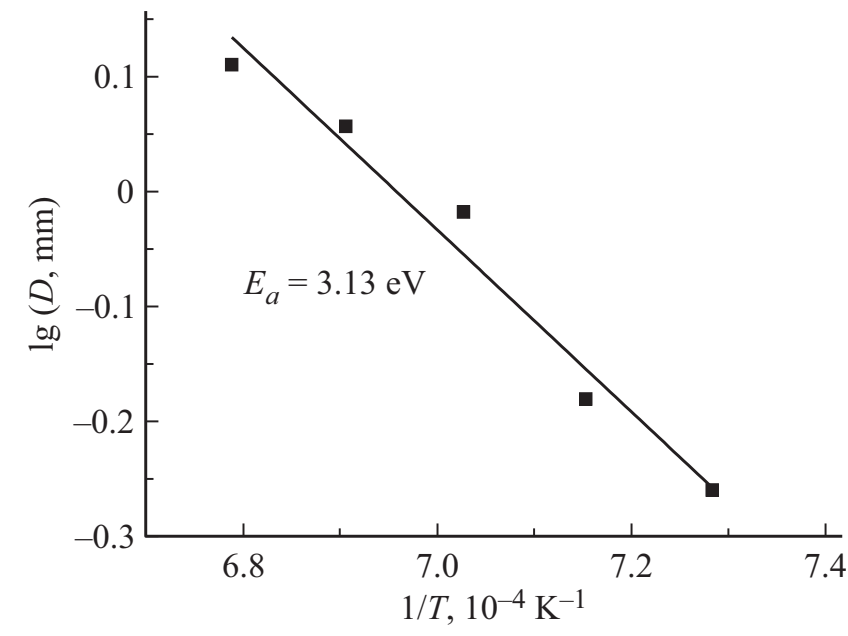

Рис. 11. Зависимость диаметра таблеток от обратной температуры спекания.

Авторы работы [5] отмечали, что присутствие естественного окисла на поверхности частиц кремниевого порошка затрудняет спекание, в то время как отжиг в восстановительной атмосфере облегчает этот процесс [11]. Проведенные нами эксперименты по спеканию нанопорошка $\mathrm{Si}$ в атмосфере аргона с 3\% водорода показали, что плотность полученных таблеток по сравнению с образцами, отожженными в $\mathrm{Ar}$, практически не изменилась. Другой эксперимент был проведен с предварительно окисленным на воздухе нанопорошком. При $T=800^{\circ} \mathrm{C}$ за 40 мин масса порошка увеличилась так, что доля оксида составила $55.3 \%$ и порошок стал более светлым. С учетом известной площади поверхности исходного порошка это означает, что в среднем на поверхности наночастиц $\mathrm{Si}$ образовался окисел толщиной $\sim 20$ нм. Плотность таблеток, полученных из окисленного порошка после спекания при $1150^{\circ} \mathrm{C}$ в $\mathrm{Ar}$, оказалась в 1.46 раз ниже, чем из неокисленного, а относительные плотности $\rho / \rho_{m}$ для этих двух порошков различались в 1.36 раза. Таким образом, подтверждается роль окисла на поверхности кремниевых частиц и возможность частично подавлять его влияние за счет восстановления $\mathrm{Si}$ в присутствии водорода.

Как известно, массоперенос при спекании происходит за счет объемной и поверхностной диффузии кремния [18]. Температурная зависимость коэффициента диффузии носит экспоненциальный характер $D_{\mathrm{Si}}=D_{0} \exp \left(-E_{a} / k T\right)$, где $E_{a}-$ энергия активации, $k$ - постоянная Больцмана, $T$ - абсолютная температура. При фиксированном времени спекания (изохронном отжиге) диффузионная длина $L \sim \sqrt{D_{\mathrm{Si}}}$. Исходя из того, что усадка материала определяется диффузионной длиной, можно оценить энергию активации коэффициента самодиффузии атомов кремния из температурной зависимости диаметра таблетки $D$. C учетом сказанного $\lg D=2528 E_{a} / T+$ const. На рис. 11 построена зависимость $\lg D=f(1 / T)$, из наклона которой получена величина $E_{a}=3.13$ эВ. Она превосходит энергию
$E_{a}=2.57$ эВ, найденную при исследовании спекания традиционного макропористого кремния [19], и занимает промежуточное положение между значениями для поверхностной $\left(E_{a}=2.21-2.50\right.$ эВ [20-22] $)$ и объемной диффузии $\left(E_{a}=4.86\right.$ эВ $\left.[15,23]\right)$. Последнее свидетельствует о смешанном механизме диффузии с возросшей ролью объемной составляющей. Этот результат согласуется с данными работы [5] по спеканию, где было показано, что имеющийся на поверхности кремниевых частиц слой окисла приводит к снижению скорости поверхностной диффузии и увеличению вклада объемной, особенно в ультрадисперсных порошках.

\section{9. Заключение}

Таким образом, путем холодной компрессии нанопорошка $\mathrm{Si}$ без использования связующих можно получать достаточно прочные таблетки пористостью 50\%, которые при высокотемпературном отжиге в инертной атмосфере при $T=1100-1250^{\circ} \mathrm{C}$ спекаются и образуют макропористый кремний с системой открытых и закрытых пор. Пористость материала начиная с $T=1100^{\circ} \mathrm{C}$, уменьшается по мере увеличения температуры и длительности отжига и достигает $\sim 10 \%$. Спекание порошка происходит за счет миграции атомов кремния по смешанному механизму поверхностной и объемной диффузии. Удельное электрическое сопротивление спеченного макропористого кремния по мере увеличения температуры отжига уменьшается на 8 порядков в диапазоне $\rho_{\mathrm{el}}=10^{8}-10^{0} \mathrm{OM} \cdot \mathrm{cм}$. Пористость и удельную площадь внутренней поверхности макропористого материала можно увеличить путем дополнительной обработки после спекания. Для этого можно использовать термическое окисление с последующим удалением окисла или растворение кремния в растворе HF при комнатной температуре.

Авторы благодарят В.Ю. Давыдова и И.А. Елисеева за проведение исследований методом комбинационного рассеяния света, В.А. Толмачева и Ю.А. Жарову за измерение толщины окисла с помощью эллипсометрии. Электронно-микроскопические исследования проводились в федеральном ЦКП „Материаловедение и диагностика в передовых технологиях“ при ФТИ им. А.Ф. Иоффе, поддержанного Министерством образования и науки РФ (Уникальный идентификатор проекта RFMEFI62117X0018).

\section{Список литературы}

[1] A. Loni. In: Handbook of Porous Silicon, ed. by L. Canham (Switzerland, Springer International Publishing, 2018) v. 1, p. 13.

[2] N. Liu, K. Huo, M.T. McDowell, J. Zhao, Y. Cui. Sci. Rep., 3, 1919 (2013).

[3] Z. Huang, N. Geyer, P. Werner, J. de Boor, U. Gösele. Adv. Mater., 23, 285 (2011). 
[4] K.W. Kolasinski. In: Handbook of Porous Silicon, ed. by L. Canham (Switzerland, Springer International Publishing, 2018) v. 1, p. 39.

[5] W.S. Coblenz. J. Mater. Sci., 25, 2754 (1990).

[6] J. Jakubowicz. In: Handbook of Porous Silicon, ed. by L. Canham (Switzerland, Springer International Publishing, 2018) v. 1, p. 111.

[7] J. Jakubowicza, K. Smardza, L. Smardz. Physica E, 38, 139 (2007).

[8] K.G. Barraclough, A. Loni, E. Caffull, L.T. Canham. Mater. Lett., 61, 485 (2007).

[9] H.J. Moller, G. Welsch. J. Am. Ceramic. Soc., 68(6), 320 (1985).

[10] D. Chakravarty, B.V. Sarada, S.B. Chandrasekhar, K. Saravanan, T.N. Rao. Mater. Sci. Eng. A, 528, 7831 (2011).

[11] S.J. Santana, K.S. Jones. J. Mater. Sci., 31, 4985 (1996).

[12] P. Bellanger, A. Sow, M. Grau, A. Augusto, J.M. Serra, A. Kaminski, S. Dubois, A. Straboni. J. Cryst. Growth, 359, 92 (2012).

[13] R. Buchwald, S. Wurzner, H.J. Moller, A. Siftja, G. Stokkan, E. Ovrelid, A. Ulyashin. Phys. Status. Solidi A, 212 (1), 25 (2015).

[14] А.А. Нечитайлов, Е.В. Астрова, Ю.А. Кукушкина, С.Ю. Каменева. ФТП, 40 (10), 1254 (2006).

[15] Основы технологии кремниевых интегральных схем. Окисление, дифбузия, эпитаксия, под ред. Р. Бургера и Р. Донована (М., Мир, 1969).

[16] A. Halimaoui. Surf. Sci. Lett., 306, L550 (1994).

[17] V. Lehmann. Electrochemistry of Silicon (Weinheim, WileyVCH, 2002) v. 277, p. 31.

[18] I. Kuzma-Filipek. In: Handbook of Porous Silicon, ed. by L. Canham (Switzerland, Springer International Publishing, 2018) v. 2, p. 901.

[19] Е.В. Астрова, Н.Е. Преображенский, С.И. Павлов, В.Б. Воронков. ФТП, 51 (1), 1213 (2017).

[20] К.Л. Гаврилюк, Ю.С. Кагановский, В.Г. Лифшиц. Кристаллография, 26, 561 (1981).

[21] M.E. Keeffe, C.C. Umbach, J.M. Blakely. J. Phys. Chem. Solids, 55, 965 (1994).

[22] P.E. Acosta-Alba, O. Kononchuk, Ch. Gourdel, A. Claverie. J. Appl. Phys., 115, 134903 (2014).

[23] Б.И. Болтакс. Диффузия и точечные дефекты в полупроводниках (Л., Наука, 1972).

\section{Fabrication of porous silicon by sintering of nanopowder}

\author{
E.V. Astrova, V.B. Voronkov, A.V. Nashchekin, \\ A.V. Parfeneva, D.A. Lozhkina, M.V. Tomkovich, \\ Yu.A. Kukushkina \\ loffe Institute, \\ 194021 St. Petersburg, Russia
}

\begin{abstract}
The well-known technique of macroporous silicon layers formation by means of electrochemical and photo-electrochemical etching of single-crystal wafers is inefficient and expensive. As an alternative method for fabrication of bulk macroporous silicon, high-temperature sintering of $\mathrm{Si}$ powder can be used. In this study, the sintering process of preliminarily cold compressed dry nanopowder (without binding additives), was investigated. The following properties of the material obtained were studied: microstructure, density, and electrical conductivity depending on the temperature and the duration of annealing. Approaches for changing porosity of the sintered samples and methods to determine the inner surface area are discussed.
\end{abstract}

Редактор Л.В. Шаронова 